\title{
Future Proofing Applied Epidemiology Workforce Training for Emergency Response. A Global Survey of Applied Epidemiologists, 2019-2020
}

\section{Amy Elizabeth Parry ( $\sim$ amy.parry@anu.edu.au )}

Australian National University https://orcid.org/0000-0001-6641-7149

\section{Martyn D Kirk}

Australian National University

\section{David N Durrheim}

University of Newcastle

\section{Babatunde Olowokure}

World Health Organization: Organisation mondiale de la Sante

\section{Samantha Colquhoun}

Australian National University

\section{Tambri Housen}

University of Newcastle

\section{Research}

Keywords: Epidemiology, public health practice, health workforce, emergency, education, emergencies

Posted Date: December 10th, 2020

DOl: https://doi.org/10.21203/rs.3.rs-122029/v1

License: (1) This work is licensed under a Creative Commons Attribution 4.0 International License. Read Full License 


\section{Abstract}

\section{Background}

Rapid and effective emergency response to address health security relies heavily on a competent and suitably trained local and international workforce. The COVID-19 pandemic has highlighted the need to ensure that the health security workforce is well equipped to tackle current and future challenges. We conducted a survey to understand whether applied epidemiology training was meeting the needs of the field epidemiological workforce.

Method

We conducted a cross sectional online survey. Purposive sampling and snowballing techniques were used to identify survey respondents. Inclusion criterion was any person who self-identified as working in an applied epidemiology role. We recruited survey respondents through an online social media campaign and partnered with the Training Programs in Epidemiology and Public Health Interventions Network (TEPHINET) to directly reach field epidemiology training programme (FETP) alumni networks. Survey topics included participant demographics, technical background, formal education level, year of epidemiology training, topics studied during epidemiology training, years of experience as an epidemiologist, and their public health/epidemiology learning. The survey was available in English and French.

Results

We received 282 responses from people with a range of formal public health and epidemiology training backgrounds. Applied epidemiology work experience of respondents spanned almost 30 years from across 64 countries. FETP alumni made up 74\% $(n=210)$ of the total. Basic outbreak and surveillance training was well reported by the respondents, however training in specialised techniques related to emergency response was not as common. Less than $50 \%$ of respondents reported receiving training in leadership and management. Training in emergency response and communications scored low across most categories. Fifty-six per cent of respondents reported learning evidence-based decision-making. FETP graduates reported higher levels of formal training in all survey topics.

\section{Conclusion}

A specific aim of our survey was to identify the training needs of the applied epidemiology workforce. Training gaps identified included leadership, communication and social skills, as well as emergency response capacity. Our survey showed that applied epidemiology workforce training must evolve to remain relevant to current and future public health challenges.

\section{Background}


Rapid and effective emergency response to address health security challenges relies heavily on a competent and suitably trained local and international workforce. $(1,2)$ The coronavirus disease 2019 (COVID-19) pandemic combined with prediction of future spill over events and other acute public health emergencies,(3) highlight the importance of having a well-equipped health security workforce to tackle these issues. Governments need to invest in strengthening their health security workforce.

Well trained field and applied epidemiologists are a crucial component of the health security workforce to prepare and effectively respond to health emergencies. $(1,4)$ The applied epidemiology workforce supports the detection, investigation, management, and control of infectious diseases, $(1,4,5)$ and have been described as "activists" who are able to rapidly transform findings into policy and action.(6)

Responsibility for applied epidemiology workforce development varies depending on the country, and may include academic institutions and departments of health. $(7,8)$ Commonly, academic institutions offer Masters of Public Health and or Epidemiology, whilst Governments largely support the Field Epidemiology Training Programme (FETP) model.(7)

The FETP model is a 'learning through doing' training approach, $(4,8,9)$ which aims to strengthen public health systems through strengthening capacity for outbreak detection and response, as well as improved disease surveillance systems for evidence based decision making.(8) FETPs vary in duration and are adapted to country needs.(10) Postgraduate courses, such as the Masters of Public Health, offer training in epidemiology, biostatistics, and some offer specific training in disaster management or humanitarian crises. $(11,12)$

The Ebola outbreak in West Africa, and more recently the COVID-19 pandemic, has highlighted the fragility of current national and international public health response models.(2) These public health events have exposed the broader socio-economic and health security implications of under-investment in public health and trained field epidemiologists.(2) Now is the time for health agencies to review health security workforce development and investment, to ensure we head into the future with an appropriately skilled and confident workforce to rapidly manage and contain public health emergencies.

In 2019, we interviewed public health experts about the needs and challenges of the epidemiology emergency response workforce. Interviewees outlined the need for collective competence and discussed the lack of training standardisation, the need for skills in leadership, communication, and also specialised training in emergency response.(13) To understand whether current applied epidemiology training was meeting the needs of the emergency response workforce and to identify where respondents believed the training gaps were, we surveyed applied epidemiologists.

\section{Methods}

We conducted a cross-sectional survey to identify the needs and required training of applied epidemiologists. This survey was part of a larger study looking at the effectiveness of the epidemiology workforce during emergency response.(14) The survey consisted of two parts, the first focusing on 
knowledge and skills learnt during participants' epidemiology education and training, and the second focused on the experience of the epidemiologist during emergency response (Figure 1). This paper describes part one of the survey.

\section{Study population}

The reference population for this survey were the global applied epidemiology workforce. We specifically targeted FETP alumni, however the survey was open to all people who had studied epidemiology and used this training in a practical setting.

For the purposes of this study, we defined any person working in an applied or field epidemiology role or acute public health responder role, as part of the 'applied epidemiology workforce'.

\section{Sampling}

Purposive sampling and snowballing techniques were used to identify survey respondents, due to the lack of a reliable sampling frame of the identified study population.(15,16)

\section{Recruitment}

Criterion for inclusion was any person who self-identified as having worked in an applied epidemiology role; FETP trainees were eligible. We recruited survey respondents through multiple sources. A YouTube video described the purpose of the study in English; this video included the option of subtitles in English or French. This video formed the basis of a social media recruitment campaign through Twitter, Linkedln, and our dedicated study Facebook page. We disseminated participation reminders eight times through these social media channels over a three-month period. We partnered with the global field epidemiology training alumni, TEPHIconnect, who ran a social media campaign mirroring our campaign. The campaign stated that any person working in an applied epidemiology role could complete the survey.

Postcards advertising the survey were distributed at the $10^{\text {th }}$ TEPHINET Global Scientific Conference, the Australian Communicable Diseases Control Conference 2019, and the European Scientific Conference on Applied Infectious Disease Epidemiology (ESCAIDE 2019). The study population were directly invited to participate in the survey by email via field epidemiology networks including TEPHIconnect and their national FETP networks. We encouraged survey respondents to forward the survey to their personal and professional network.

\section{Consent}

Participation in this study was voluntary; participants were directed to plain language information sheets, available online in French and English, prior to being able to access the survey. Each participant provided online consent prior to obtaining access to the survey questions. Respondents had the option to navigate the survey and remove or change answers prior to submission. 


\section{Ethics}

This survey was approved by the Australian National University Human Research Ethics Committee, ID 2019-068.

\section{Data collection}

We used findings from key informant interviews conducted in $2019(13,17)$ and literature reviews to inform the development of the survey questions. Open and closed ended questions were developed and then reviewed by key informant interviewees.(18) We pre-tested the survey with 11 people; 10 pre-testers had a history of working in emergency settings, one had not.

The survey was divided into three modules: demographics, epidemiology-training, and deployment experience. This paper will focus on the first two modules. The demographics module included age, gender identification, citizenship, formal education, technical background, years of epidemiology experience, and whether they had emergency response experience. For FETP trainees and graduates, we asked about their highest FETP level achieved, based on the three FETP levels; frontline ( $\leq 6$ months), intermediate (9 months- 1 year), and advanced (2 years).(9)

The epidemiology-training module focused on epidemiology and public health training. This module included five broad areas of epidemiology training, each with a checkbox list of specific training items: surveillance (6 items), data analysis and assessment (15 items), leadership (9 items), social and communication skills (11 items), and emergency response (14 items). We termed "soft skills" as "social and communication skills". Terminology for these skills vary; we decided 'interpersonal skills'(19) was a too narrow definition for this study.

The epidemiology-training module included free-text fields where respondents could identify further training gaps for each area, provide further comments, or list additional training received. Open-ended questions also included opinion questions regarding respondent's knowledge and skills gained during their training, and whether they were appropriate and adequate for emergency response.

The survey was created and tested in English and then translated into French. Translation was then rechecked by a French-English speaker to ensure accuracy of meaning. The survey was self-administered online by respondents via REDCap (Research Electronic Data Capture)(20) between October 2019February 2020. No incentives were provided for participation.

\section{Data analysis}

Survey data was analysed descriptively in Microsoft Excel and Stata15 (TX:StataCorp)(21) Data were analysed to explore associations within and between respondents. We compared self-recounted epidemiology training between FETPs and non-FETP and gender. Reported FETP levels were not subanalysed due to low numbers of respondents from frontline and intermediate programs. We used Pearson chi squared (Chi2) to test for significance between categorical variables. Answers to open ended 
questions were analysed using Nvivo11(22), text was coded and common themes were developed iteratively. $(23,24)$

We used the World Health Organization (WHO) six regions to categorise geographical areas; the Regional Office for Africa (AFRO), Regional Office for the Eastern Mediterranean (EMRO), the Regional Office for Europe (EURO), Pan American Health Organization (PAHO), South-East Asia Regional Office (SEARO), and the Western Pacific Region Office (WPRO).(25)

\section{Results}

Three hundred and thirty individuals consented to participate, of which $282(85 \%)$ completed the survey; 268 (95\%) respondents completed the survey in English and 14 (5\%) in French. Although the denominator for this survey was unknown due to our multiple recruitment methods, the primary means for survey distribution was the TEPHIconnect field epidemiology database, with 1700 registered active members as of September 2019. Using this as an indicative sampling frame, and the response rate from a previous unpublished survey by TEPHIconnect of $9.8 \%$, we assessed that the final sample size of 282 in this study would to lead to estimates of a single proportion with a $95 \%$ confidence interval, with precision of $₫ 6 \%$, after employing the finite population correction.

There were equal numbers of respondents recruited from the combined social media platforms (Facebook, Twitter, and LinkedIn) ( $n=104,32 \%)$ and through the TEPHINET/TEPHIconnect alumni network ( $n=105,32 \%)$. Respondents alerted to the survey through country specific FETPs contributed $22 \%$ $(n=71)$ of the responses. Personal or professional contact snowballing identified $13 \%(n=42)$ of respondents.

\section{Demographics}

Gender distribution of respondents was almost equal, with $51 \%$ female $(n=144)$. The median age of respondents was 39 (range: 23-77 years) (Table 1). Gender and age distribution were similar between FETP and non-FETP respondents, and education level.

Epidemiology was the technical background most frequently reported by respondents, followed by public health (Table 1). Respondents predominately reported that they held post graduate and/or Doctorate level qualifications ( $n=258,91.5 \%$ ) (Table 2). With the exception of laboratory specialists and social scientists, there were no significant differences between gender and reported technical backgrounds. There were twice as many male laboratory specialists $(n=23,65.7 \%, p=0.028)$ and significantly more female social scientists $(n=11,78.5 \%, p=0.038)$. Gender disparity between other technical backgrounds was not observed, however, numbers were small when broken down by profession. There were more females who identified as epidemiologists ( $n=120,53 \%)$, nurses $(n=16,64 \%)$, and public health specialists $(n=84,53 \%)$.

Table 1: Demographic characteristics of epidemiology emergency response survey respondents, 2019$2020(n=282)$ 


\begin{tabular}{|c|c|c|}
\hline Category & Variable & Number (\%) \\
\hline \multicolumn{3}{|l|}{ Gender } \\
\hline & Female & $144(51.1 \%)$ \\
\hline & Male & 135 (47.9\%) \\
\hline & Non-conforming & $0(0 \%)$ \\
\hline & Prefer not to answer & $3(1.1 \%)$ \\
\hline \multicolumn{3}{|c|}{ Age (years) } \\
\hline & $<20$ & $0(0 \%)$ \\
\hline & $20-29$ & $18(6.4 \%)$ \\
\hline & $30-39$ & $140(49.6 \%)$ \\
\hline & $40-49$ & $78(27.7 \%)$ \\
\hline & $50-59$ & $37(13.1 \%)$ \\
\hline & $60-69$ & $7(2.5 \%)$ \\
\hline & $70+$ & $2(0.7 \%)$ \\
\hline \multicolumn{3}{|c|}{ Technical background* } \\
\hline & Epidemiology & 225 (79.8\%) \\
\hline & Public Health & $158(56 \%)$ \\
\hline & Medicine & $70(24.8 \%)$ \\
\hline & Laboratory & $35(12.4 \%)$ \\
\hline & Nursing & $25(8.9 \%)$ \\
\hline & Data science & $21(7.4 \%)$ \\
\hline & Veterinary & $19(6.7 \%)$ \\
\hline & Social Science & $14(5.0 \%)$ \\
\hline & Other & $23(8.2 \%)$ \\
\hline
\end{tabular}

*multiple technical backgrounds per respondent

Respondents came from 64 countries; the highest number of respondents reported being from the United States of America $(n=47,16.7 \%)$, Australia $(n=39,13.8 \%)$, and Nigeria $(n=20,7.1 \%)$. Respondents came from all WHO regions, with the America's (PAHO) contributing the highest participation (Figure 2). 
Respondents in AFRO and SEARO were more likely to be male ( $n=51,76 \%, n=23,85 \%$ respectively), compared to more female respondents in PAHO and WPRO ( $n=53,69 \%, n=41,71 \%$ respectively). Gender distribution within EMRO and EURO respondents was equal. The age distribution of respondents was similar between regions. Across all regions, FETP respondents made up between $65-89 \%$ of respondents (Figure 2).

Respondents reported a variety of formal public health and epidemiology training, ranging from Masters Programmes, PhDs, FETPs, Physician Public Health Training, and short courses in specified public health and epidemiology topics (Table 2). FETP trainees/ graduates made up $74 \%(n=210)$ of respondents, of whom $11 \%(n=32)$ were trainees at the time of survey participation. Of the 210 FETP's, 93\% $(n=189)$ reported to have studied the advanced model (Table 2). Respondents largely had graduated from their FETP within the past 10 years (74.4\%) (Table 2), however graduation went as far back as 1992.

Respondents reported varying periods of epidemiology experience with $40 \%(n=112)$ reporting less than five years of experience, and $20 \%(n=59)$ with more than 12 years of experience (Table 2$)$.

\section{Table 2: Professional background characteristics of Epidemiology Emergency Response Survey respondents, 2019-2020 ( $n=282)$}




\begin{tabular}{|c|c|c|}
\hline Category & Variable & Number (\%) \\
\hline \multicolumn{2}{|c|}{ Epidemiology and Public heath training* } & $n=282$ \\
\hline & Master of Public Health (or similar) & $92(32.6 \%)$ \\
\hline & Other relevant Masters & $13(4.6 \%)$ \\
\hline & Public Health Physician training & $10(3.5 \%)$ \\
\hline & $\mathrm{PhD}$ & $18(6.4 \%)$ \\
\hline & Field Epidemiology Training Programme (FETP) & $210(74.5 \%)$ \\
\hline \multicolumn{2}{|c|}{ FETP alumni } & $n=282$ \\
\hline & Yes & $178(63.1 \%)$ \\
\hline & Trainee at time & $32(11.3 \%)$ \\
\hline & No & $72(25.5 \%)$ \\
\hline \multicolumn{2}{|c|}{ FETP level } & $\mathrm{n}=210$ (including trainees) \\
\hline & Advanced (2 years) & $189(90 \%)$ \\
\hline & Intermediate (9months - 1 year) & $7(3.4 \%)$ \\
\hline & Frontline (<6 months) & $7(3.4 \%)$ \\
\hline & Unanswered & $7(3.4 \%)$ \\
\hline \multicolumn{2}{|c|}{ Years since FETP graduation } & $n=210$ \\
\hline & 10 or less & $157(74.8 \%)$ \\
\hline & $10+$ & $37(17.6 \%)$ \\
\hline & Unanswered & $16(7.6 \%)$ \\
\hline \multicolumn{2}{|c|}{ Epidemiology experience } & $n=282$ \\
\hline & $<1$ years & $12(4.3 \%)$ \\
\hline & $1<2$ years & $23(8.2 \%)$ \\
\hline & $2-<5$ years & 77 (27.3\%) \\
\hline & $5-<8$ years & $64(22.7 \%)$ \\
\hline & $8<<12$ years & $42(14.9 \%)$ \\
\hline & $12+$ years & 59 (20.9\%) \\
\hline & not applicable & $4(1.4 \%)$ \\
\hline & Unanswered & $1(0.4 \%)$ \\
\hline
\end{tabular}


*multiple training types per respondent

\section{Epidemiology Training}

\section{Outbreak and Surveillance}

Basic outbreak and surveillance training was commonly reported by the respondents, however less common was targeted training in emergency response surveillance, community based surveillance or syndromic surveillance (Table 3a). When comparing the respondents who had completed an FETP with those who had not participated in an FETP, FETP graduates reported higher levels of formal training in all surveillance and outbreak investigation questions (Table 3a).

Table 3: Reported epidemiology training, comparison between FETP and non-FETP epidemiology emergency response survey respondents 2019-2020 ( $n=282)$ 


\begin{tabular}{|c|c|c|c|c|c|c|c|c|}
\hline Section & Category & Topic & $\begin{array}{l}\text { Total } \\
\mathrm{n}=\mathbf{2 8 2}\end{array}$ & $\begin{array}{l}\text { Total } \\
\%\end{array}$ & $\begin{array}{l}\text { Non } \\
\text { FETP } \\
\mathrm{n}=72\end{array}$ & $\begin{array}{l}\text { Non } \\
\text { FETP } \\
\%\end{array}$ & $\begin{array}{l}\text { FETP } \\
\mathrm{n}=178\end{array}$ & $\begin{array}{l}\text { FETP } \\
\%\end{array}$ \\
\hline \multirow[t]{7}{*}{ a } & \multicolumn{8}{|c|}{$\begin{array}{l}\text { Training in outbreak and } \\
\text { surveillance }\end{array}$} \\
\hline & & $\begin{array}{l}\text { Basic principles of } \\
\text { surveillance }\end{array}$ & 262 & 92.9 & 58 & 80.6 & 173 & 97.2 \\
\hline & & $\begin{array}{l}\text { Syndromic } \\
\text { surveillance }\end{array}$ & 165 & 58.5 & 23 & 31.9 & 118 & 66.3 \\
\hline & & $\begin{array}{l}\text { Community based } \\
\text { surveillance }\end{array}$ & 157 & 55.7 & 34 & 47.2 & 104 & 58.4 \\
\hline & & $\begin{array}{l}\text { Emergency response } \\
\text { surveillance }\end{array}$ & 168 & 59.6 & 29 & 40.3 & 119 & 66.8 \\
\hline & & $\begin{array}{l}\text { Outbreak investigation } \\
\text { steps }\end{array}$ & 250 & 88.7 & 51 & 70.8 & 168 & 94.4 \\
\hline & & $\begin{array}{l}\text { Outbreak investigation } \\
\text { methods }\end{array}$ & 238 & 84.4 & 47 & 65.3 & 160 & 89.9 \\
\hline \multirow[t]{16}{*}{ b } & \multicolumn{8}{|c|}{ Training in analysis and methods } \\
\hline & & Rapid survey & 162 & 57.4 & 35 & 48.6 & 107 & 60.1 \\
\hline & & Mortality survey & 84 & 29.8 & 21 & 29.2 & 51 & 28.6 \\
\hline & & Nutrition survey & 52 & 18.4 & 13 & 18.1 & 32 & 18 \\
\hline & & Other survey & 107 & 37.9 & 17 & 23.6 & 75 & 42.1 \\
\hline & & $\begin{array}{l}\text { Denominator } \\
\text { estimation }\end{array}$ & 83 & 29.4 & 20 & 27.8 & 52 & 29.2 \\
\hline & & Needs assessment & 101 & 35.8 & 24 & 33.3 & 66 & 34.1 \\
\hline & & Risk assessment & 152 & 53.9 & 34 & 47.2 & 98 & 55.1 \\
\hline & & $\begin{array}{l}\text { Managing complex } \\
\text { datasets }\end{array}$ & 78 & 27.7 & 23 & 31.9 & 47 & 26.4 \\
\hline & & $\mathrm{R}$ & 34 & 12.1 & 12 & 16.7 & 18 & 10.1 \\
\hline & & Stata & 123 & 43.6 & 28 & 38.9 & 79 & 44.4 \\
\hline & & Epi Info & 205 & 72.7 & 31 & 43.1 & 149 & 83.7 \\
\hline & & Excel & 187 & 66.3 & 35 & 48.6 & 131 & 73.6 \\
\hline & & Data visualisation & 112 & 39.7 & 26 & 36.1 & 67 & 37.6 \\
\hline & & Transmission trees & 36 & 12.8 & 11 & 15.3 & 20 & 11.2 \\
\hline & & Spatial analysis & 71 & 25.2 & 19 & 26.4 & 38 & 21.4 \\
\hline
\end{tabular}


c Training in leadership and management

\begin{tabular}{|c|c|c|c|c|c|c|c|}
\hline & $\begin{array}{l}\text { Evidence based } \\
\text { decision making }\end{array}$ & 159 & 56.4 & 35 & 48.6 & 108 & 60.7 \\
\hline & Mentoring & 98 & 34.8 & 10 & 13.9 & 74 & 41.6 \\
\hline & Leadership & 130 & 46.1 & 19 & 26.4 & 91 & 51.1 \\
\hline & Managing a team & 119 & 42.2 & 20 & 27.8 & 85 & 47.8 \\
\hline & Peer teaching & 93 & 33 & 9 & 12.5 & 70 & 39.3 \\
\hline & Team work & 184 & 65.2 & 33 & 45.8 & 126 & 70.8 \\
\hline & Prioritisation & 87 & 30.9 & 17 & 23.6 & 60 & 33.7 \\
\hline & $\begin{array}{l}\text { Delegating } \\
\text { responsibility }\end{array}$ & 73 & 25.9 & 13 & 18.1 & 52 & 29.2 \\
\hline & Partner coordination & 84 & 29.8 & 15 & 20.8 & 60 & 33.7 \\
\hline & Reflective practices & 33 & 11.7 & 8 & 11.1 & 21 & 11.8 \\
\hline \multirow[t]{11}{*}{$d$} & $\begin{array}{l}\text { Training in social and } \\
\text { communication skills }\end{array}$ & & & & & & \\
\hline & $\begin{array}{l}\text { Basic scientific } \\
\text { communication skills }\end{array}$ & 244 & 86.5 & 48 & 66.7 & 166 & 93.3 \\
\hline & $\begin{array}{l}\text { Practical field } \\
\text { communication skills }\end{array}$ & 149 & 52.8 & 24 & 33.3 & 107 & 60.1 \\
\hline & Media communication & 136 & 48.2 & 24 & 33.3 & 94 & 52.8 \\
\hline & Cultural competency & 72 & 25.5 & 22 & 30.6 & 42 & 23.6 \\
\hline & Participant consent & 152 & 53.9 & 30 & 41.7 & 100 & 56.2 \\
\hline & Stress management & 60 & 21.3 & 9 & 12.5 & 43 & 24.2 \\
\hline & Social media & 32 & 11.3 & 5 & 6.9 & 22 & 12.4 \\
\hline & Interview techniques & 144 & 51.1 & 31 & 43.1 & 95 & 53.4 \\
\hline & Ethics & 169 & 59.9 & 40 & 55.6 & 111 & 62.4 \\
\hline & Relationship building & 62 & 22 & 14 & 19.4 & 38 & 21.3 \\
\hline \multirow[t]{3}{*}{$E$} & $\begin{array}{l}\text { Training in emergency response } \\
\text { training }\end{array}$ & & & & & & \\
\hline & $\begin{array}{l}\text { Role of the } \\
\text { epidemiologist during } \\
\text { emergency response }\end{array}$ & 169 & 59.9 & 33 & 45.8 & 113 & 63.5 \\
\hline & Epidemiology of & 166 & 58.9 & 32 & 44.4 & 114 & 64 \\
\hline
\end{tabular}


public health disasters

\begin{tabular}{|c|c|c|c|c|c|c|}
\hline $\begin{array}{l}\text { Humanitarian } \\
\text { principles }\end{array}$ & 67 & 23.8 & 18 & 25 & 42 & 23.6 \\
\hline $\begin{array}{l}\text { Principles of } \\
\text { escalation / scaling a } \\
\text { response }\end{array}$ & 45 & 16 & 9 & 12.5 & 30 & 16.9 \\
\hline $\begin{array}{l}\text { Methods of data } \\
\text { collection in an } \\
\text { emergency }\end{array}$ & 147 & 52.1 & 31 & 43.1 & 96 & 53.9 \\
\hline $\begin{array}{l}\text { Ethics during } \\
\text { emergencies }\end{array}$ & 82 & 29.1 & 18 & 25 & 53 & 29.8 \\
\hline $\begin{array}{l}\text { IMS - Incident } \\
\text { Management System }\end{array}$ & 73 & 25.9 & 14 & 19.4 & 46 & 25.8 \\
\hline $\begin{array}{l}\text { EOC role- Emergency } \\
\text { Operations Centre }\end{array}$ & 93 & 33 & 17 & 23.6 & 63 & 35.4 \\
\hline $\begin{array}{l}\text { IHR - International } \\
\text { Health Regulations }\end{array}$ & 121 & 42.9 & 15 & 20.8 & 87 & 48.9 \\
\hline $\begin{array}{l}\text { HeRAMS: Health } \\
\text { Resources Availability } \\
\text { Monitoring System }\end{array}$ & 11 & 3.9 & 1 & 1.4 & 8 & 4.5 \\
\hline $\begin{array}{l}\text { EWARS: Early } \\
\text { Warning, Alert and } \\
\text { Response System } \\
\text { (EWARS in a box) }\end{array}$ & 79 & 28 & 12 & 16.7 & 58 & 32.6 \\
\hline $\begin{array}{l}\text { Personal safety (use } \\
\text { of PPE - personal } \\
\text { protective equipment) }\end{array}$ & 130 & 46.1 & 26 & 36.1 & 88 & 49.4 \\
\hline $\begin{array}{l}\text { Border control (POE - } \\
\text { point of entry) }\end{array}$ & 46 & 16.3 & 8 & 11.1 & 30 & 16.9 \\
\hline
\end{tabular}

FETP: Field Epidemiology Training Programme

When commenting on outbreak and surveillance training gaps and challenges, respondents reported the need for additional opportunities for knowledge consolidation and skill development (Box 1).

Respondents also stated that the teaching needed to be grounded within the political and social context of outbreak and surveillance (Box 1). Training in alternate surveillance techniques such as syndromic and community based surveillance was discussed as lacking and respondents requested more training in different types of response such as to environmental and chemical and radiological disasters (Box 1).

Box 1: Outbreak and surveillance training gaps reported by epidemiology emergency response survey respondents, 2019-2020 
Application "I feel we were given enough knowledge, but did not apply it in practice."

[training] "was mostly based around field epidemiology in stable, developing world settings. It's mostly related to the work of government departments."

"I believe that I wanted to have more opportunities to apply in practice what I learned theoretically."

"While we acquire lots of knowledge, the practical competencies could be more developed by being in the field during the training program"

"The knowledge and skills learnt were more geared toward outbreak response ... Even then, looking back they were somewhat outdated and didn't necessarily reflect the political culture within which outbreaks occur."

Knowledge

[I wanted training] "related to chemical, radiological and explosive emergencies"

Data analysis

Training on estimation of population size during emergencies was reported by only $29.4 \%(n=83)$ of respondents, this was similar for both FETP $(n=52,29.2 \%)$ and non-FETP $(n=20,27.8 \%)$ respondents. Almost $28 \%(n=78)$ of respondents had received training in managing complex datasets (Table $3 \mathrm{~b})$.

Thirty-six percent $(\mathrm{n}=101)$ of respondents reported receiving training in needs assessments, with $53.9 \%$ $(n=152)$ trained in risk assessments. Training in survey development and implementation of specialised surveys, such as nutrition and mortality surveys, were uncommonly reported by respondents $(18.4 \% \mathrm{n}=52$, and $29.8 \% \mathrm{n}=84$ respectively), as were analytical techniques such as transmission trees $(12.8 \% \mathrm{n}=36)$ and spatial analysis $(25.2 \% \mathrm{n}=71)$ (Table $3 \mathrm{~b})$.

Epi Info was the most commonly reported statistical package taught $(72.7 \% \mathrm{n}=205)$, followed by Microsoft Excel $(66.3 \% \mathrm{n}=187)$ and Stata $(43.6 \% \mathrm{n}=123)$ (Table 3b). There was a difference between FETP and non-FETP graduates regarding reported training in statistical packages; $83.7 \%(n=149)$ of FETP respondents compared to $43.1 \%(n=31)$ non-FETP respondents reported learning Epi Info. Excel training was reported by $73.6 \%(n=131)$ of FETPs compared to $48.6 \%(n=35)$ of non-FETP respondents.

When asked where they believed there were gaps in their epidemiology training in regards to data analysis, respondents listed training in data analysis and managing complex data skills; specifically, $R$ statistical software training, population denominator estimation, spatial analysis, and mapping skill development.

\section{Leadership and management}

Survey questions relating to leadership and management training had varying responses. Sixty-five percent $(n=184)$ of respondents reported teamwork was part of their epidemiology training, and $56.4 \%$ $(n=159)$ reported learning evidence based decision-making. Responses to the remaining eight items in the leadership and management module indicated that most training programs did not include training in 
leadership and management skills, with under $50 \%$ of respondents saying they learnt these skills during their training, with training in reflective practices reported by only $11.7 \%(n=33)$ of respondents (Table $3 c)$.

FETP respondents reported a higher percentage of training in all leadership categories compared to nonFETP, especially in mentoring and peer teaching (Table 3c). Within each category in this section, males reported much higher rates of learning, with the exception of peer teaching. Of note, $45.9 \%(n=62)$ of male respondents reported learning mentoring, compared to $24.3 \%(n=35)$ of female respondents, $61.5 \%$ $(n=83)$ of males compared to $31.3 \%(n=45)$ of females reported learning leadership, and $34.1 \%(n=46)$ of males and $17.4 \%(n=25)$ of females reported learning to delegate responsibility during their training (Table 4).

Table 4: Reported training in leadership, comparison of epidemiology emergency response survey by gender, 2019-2020 ( $n=282)$

\begin{tabular}{|lll|}
\hline Topic & Female & Male \\
& $\mathrm{n}=144(\%)$ & $\mathrm{n}=135(\%)$ \\
\hline Evidence based decision making & $77(53.5 \%)$ & $80(59.3 \%)$ \\
\hline Mentoring & $35(24.3 \%)$ & $62(45.9 \%)$ \\
\hline Leadership & $\mathbf{4 5 ( 3 1 . 3 \% )}$ & $\mathbf{8 3}(\mathbf{6 1 . 5 \% )}$ \\
\hline Managing a team & $\mathbf{4 5 ( 3 1 . 3 \% )}$ & $\mathbf{7 2 ( 5 3 . 3 \% )}$ \\
\hline Peer teaching & $51(35.4 \%)$ & $42(31.1 \%)$ \\
\hline Team work & $89(61.8 \%)$ & $92(68.1 \%)$ \\
\hline Prioritisation & $38(26.4 \%)$ & $47(34.8 \%)$ \\
\hline Delegating responsibility & $\mathbf{2 5 ( 1 7 . 4 \% )}$ & $\mathbf{4 6}(\mathbf{3 4 . 1} \%)$ \\
\hline Partner coordination & $37(25.7 \%)$ & $45(33.3 \%)$ \\
\hline
\end{tabular}

\section{Social and communication}

Training in basic scientific communication such as report writing and presentation preparation was common amongst respondents $(n=244,86.5 \%)$. Training in other communication techniques was less frequently reported; including training in practical communication in the field $(n=149,52.8 \%)$, media communication $(n=136,48.2 \%)$, cultural competence $(n=72,25.5 \%)$, and social media communication $(n=32,11.3 \%$ ) (Table 3d). Training in stress management and relationship building were reported by just over $20 \%$ ( $n=60$ and $n=62$ respectively). Interview techniques, consent, and practical ethical approaches to field work were reported by just above half of the respondents (Table 3d). With the exception of cultural competency, non-FETPs reported less training than FETPs to each question in this section (Table $3 d$ ). 
Answers to open-ended questions asking respondents about social and communication training needs, highlighted recognition for the need for further training in in this area (Box 2). Further training in the use of traditional media and social media were commonly stated as essential training for epidemiologists (Box 2). Respondents also stated that training with a focus on cultural, political, and contextual understanding was needed, as were training on qualitative research methods, stress management, and prioritisation (Box 2).

\section{Box 2: Social and communication training gaps reported by epidemiology emergency response survey respondents, 2019-2020}

\begin{tabular}{|l|l|}
\hline Communication & $\begin{array}{l}\text { "I think a really valuable skill that should be taught in epidemiology is how to } \\
\text { influence others with the data story. This isn't about most fancy, complicated } \\
\text { analysis, but about working out what's important in the data for decision-making." }\end{array}$ \\
\begin{tabular}{|l} 
Social science \\
and \\
anthropological \\
skills
\end{tabular} & $\begin{array}{l}\text { "My training as an anthropologist and social scientist significantly enhanced my } \\
\text { skills as an epidemiologist. These are new concepts and under recognized and } \\
\text { underused" }\end{array}$ \\
$\begin{array}{l}\text { "I will welcome more knowledge in behavioural change and anthropology during } \\
\text { the training" }\end{array}$ \\
\hline
\end{tabular}

\section{Emergency response}

Fourteen emergency response training items were listed in the survey, half $(n=7)$ of which were reported by less than $30 \%$ of respondents each (Table $3 \mathrm{e}$ ). Non-FETP respondents reported less training than FETP graduates in each of these emergency response categories (Table 3e).

When respondents were asked whether they believed emergency response training should be a core component of applied epidemiology training, almost $75 \%(n=211)$ replied yes, and $18 \%(n=50)$ suggested it should be optional.

Despite relatively low proportions of respondents having formally studied the listed emergency response topics, $64 \%$ (n=181) agreed or strongly agreed that their epidemiology training gave them the required knowledge to work as an epidemiologist during emergency response (Figure 3), and 65\% ( $n=172$ ) believed they had learnt the required skills for epidemiology emergency response (Figure 4). FETP respondents were more likely to answer positively to these questions than non-FETP (Figures 3 and 4).

When asked what was missing from their epidemiology training, respondents suggested emergency response training. Specifically, respondents asked for training on the epidemiology role during emergency response, who should respond to emergencies and what characteristics were needed, emergency response epidemiology methods, humanitarian principles, as well as teaching on the emergency response structure (Box 3).

Box 3: Emergency response training gaps reported by epidemiology emergency response survey respondents, 2019-2020 
Emergency "Being fit for the field i.e. not everyone who has completed the program should be in the response field."

"Specific things like bioterrorism and natural disasters and hurricane response"

"Critical skills to data analysis and collection during an emergency, rarely having a denominator, working with dirty data, working with MoH's [Ministry of Health] without statistical packages."

"Did not learn enough about the different approaches and methods that are/should be used in an emergency setting vs a regular ongoing surveillance or outbreak response setting."

"Thinking systems in the middle of an emergency"

"A session on the realities of an emergency situation would be useful."

"There was minimal relevant to emergency response or low resource settings."

Response

structure
"How humanitarian responses are structured - what is happening around you in such a response and concrete feedback about where epi skills and information can serve those components."

"There were no emergency response topics covered in my epi training... no mention of IHR [International Health Regulations]"

Role
"Even at the advanced level and despite being "on the ground", does not have the capacity of those trained in the roles of the epidemiologist in emergency situations or health crises, in rapid interventions."

"In a situation with an environmental disaster (e.g. air pollution), the epidemiologist has no preparation on his role in such an event. Other areas: Mass casualty, major water contamination, exposure to chemicals due to explosions etc... responders are prepared, but the epidemiologist is not."

\section{Discussion}

One aim of our survey was to identify the training needs of the applied epidemiology workforce. Our findings indicate that respondents believe their training in outbreak and surveillance, regardless of different training models, to be sufficient. Respondents did however identify training gaps in the areas of social and communication skills, leadership and management, and emergency response. Additionally, respondents identified that learning methods needed to focus more on practical skill application.

The COVID-19 pandemic has reminded us that communication skills are vital to connect with the public and successfully implement control measures.(26-28) Communication skills have numerous applications, such as communicating risk to the target population, and designing messages that will support decision makers to implement control measures. As the applied epidemiology definition by 
Thacker and Buffington(6) states, applied epidemiology is about "transforming findings to policy and action", and as one of the respondents wrote, "it is not just about collecting data but it is about influencing others with the story". This survey identified training in cultural competency, socio-political context, and anthropology as a gap. This weakness was also documented in a study of emergency response epidemiologists who responded to Ebola in West Africa,(19) and a study looking to understand outbreak investigation training.(29) Despite the crucial need for these skills to function optimally as applied epidemiologists, survey respondents highlighted that these skills were not routinely taught in their epidemiology training.

Leadership and management skills are crucial for responding to public health events; one of the aims of FETPs is to train future public health leaders. $(8,30,31)$ Leadership and management is a core FETP competency, however, all variables in the leadership and management section of our survey reported low inclusion, except for teamwork. A key characteristic of applied epidemiology is making evidence based decisions, however only about half of respondents reported training in this. A study of West Africa Ebola response epidemiologists,(19) as well as a study of epidemiology graduates in the United States also found that leadership was a common training gap.(32)

Interestingly, despite no significant gender difference between respondents, education level, or education type, the questions on leadership and decision-making were the only variables with differing gender results. This raises questions on whether leadership has the same meaning or interpretation across genders. This gender division may be linked to stereotypes and individual definitions around what constitutes leadership.(33-35) Traditionally, leadership has been linked to masculine traits, which then also devalue the feminine style of leadership. $(34,35)$ Johnson and Blair discuss how COVID-19 is shifting this understanding of leadership.(34) This idea will be further explored in interviews with field epidemiologists in another publication.

When focusing on technical epidemiology skills, few respondents reported training in denominator estimation or specialised surveys such as mortality or nutrition surveys. Médecins Sans Frontières (MSF) have listed key competencies for epidemiologists to respond to an emergency; these state practical research methods experience, as well as survey development and implementation (including mortality and nutritional surveys).(36) One of the first jobs of an applied epidemiologist is to understand the population. FETP trainees trained to respond to public health events, without training in population estimation, population surveys, risk and needs assessment, would struggle to respond to public health emergencies. Standardisation of curriculum and core concepts is needed.(37)

Training in practices that support the applied epidemiology workforce to remain strong and healthy and prevent burnout, such as stress management and reflective practices, were also crucially low. Many countries struggle to retain field epidemiologists due to occupational burnout or career path limitations. $(7,31,38)$ Ryu's study on field epidemiology occupational stress, suggests that burnout is a very real concern given the frontline nature of outbreak and emergency response, with half of their respondents having experienced it.(7) 
Respondents reported low levels of training in emergency response topics, however they said they were confident in their learnt emergency response skills and knowledge. Overwhelmingly, when writing about what skill and knowledge development were missing from applied epidemiology training, skills in emergency response, response structure and the role of the epidemiologist were prevalent. Emergency response, whether it be a local or international public health emergency, should be a core competency of applied epidemiologists, who are often first responders. To be adequately equipped this workforce needs more specialised skills in emergency response which seems to be neglected in the current models of applied epidemiology training. Continuous professional development activities should be considered for this workforce to ensure skills and knowledge is maintained and developed.

Although this survey focused on individuals' training experience, our findings can be used to explore the larger workforce future challenges. We need to consider what capacities are required for the management and control of public health emergencies, not just the individual needs of each trainee.(39) Investment in a resilient applied epidemiology workforce means ensuring the workforce have the skills and knowledge needed to fulfil the various health security roles they will play now and in the future. $(5,29,32,37)$

\section{Study limitations}

We recognised some limitations with this study and attempted to mitigate their impact on our findings. Data collection was through an opt-in self-administered online survey. The survey was not offered in any other format, therefore those without internet access were not able to participate, which may have excluded people working at the community level. We attempted to mitigate selection-bias introduced because of the lack of a sampling frame by using multiple sources and methods for participant recruitment. We also offered the survey in two languages, French and English, as these are the common languages used during recent international emergency responses. We are unable to generalise our findings across the applied epidemiology workforce, however, our sample size was large enough to find common themes.

A limitation to this study was obtaining an accurate target population denominator. The applied epidemiology workforce in most countries is informal and often undocumented with the definition of 'epidemiologist' varying between individuals and organizations. The title of epidemiologist is largely through self-identification. Due to this limitation, we designed a cross-sectional survey distributed through professional networks. The target study population was defined as anyone self-identifying as having worked in an applied epidemiology role. However, because of this design we are unable to comment on how survey respondents differed from non-respondents.

As the timing of the survey was not during or immediately after the respondents' training in epidemiology, recall bias may have affected the information obtained. Respondents also had varying years and types of experience and time since graduation. This timing may have advantages as respondents had time to reflect on what went well and what could be improved. $(40,41)$ 
In recent years, FETP training has expanded to three levels including a frontline and intermediate program; few representatives from these programs accessed the survey. Future applied epidemiology workforce surveys should be targeted at graduates of these programs

In spite of the limitations mentioned, this study offers insight into gaps in training for epidemiologists, supporting other literature and findings in this area.

\section{Conclusion}

Our survey has shown that applied epidemiology training needs to evolve to provide capacity and skills to respond to dynamic and complex emergencies. There is a need to address the identified training gaps in leadership, communication and social skills, as well as emergency response. This will strengthen the applied epidemiology workforce, as well as the health systems they function within and the local, national, regional and global emergencies they respond to. Continuous professional development activities must also be available to support the current workforce adapt, as well as augment new graduates to be suitably skilled for the challenges ahead.

\section{Abbreviations}

AFRO: Regional Office for Africa

COVID-19: Coronavirus Disease 2019

EMRO: Regional Office for the Eastern Mediterranean

EOC: Emergency Operations Centre

ESCAIDE: European Scientific Conference on Applied Infectious Disease Epidemiology

EURO: Regional Office for Europe

EWARS: Early Warning, Alert, and Response System

FETP: Field Epidemiology Training

HeRAMS: Health Resources Availability Monitoring System

IHR: International Health Regulations

IMS: Incident management systems

MPH: Master of Public Health

MSF: Médecins sans Frontières 
PAHO: The Pan American Health Organization

POE: Point of Entry

PPE: Personal protective equipment

REDCap: Research Electronic Data Capture

SEARO: South-East Asia Regional Office

TEPHINET: Training Programs in Epidemiology and Public Health Interventions Network

TEPHIconnect: TEPHINET alumni network

WHO: World Health Organization

WPRO: Western Pacific Region Office

\section{Declarations}

Ethics approval and consent to participate: This survey was approved by the Australian National University Human Research Ethics Committee, ID 2019-068. Each participant completed a consent form prior to participation.

Consent for publication: not applicable

Availability of data and materials: All data relevant to this manuscript are included within the manuscript tables, figurers and/or reference links.

Competing interests: The authors declare that they have no competing interests.

Funding: This research received no specific grant from any funding agency in the public, commercial or not-for-profit sectors. AP receives Commonwealth and ANU science merit scholarships, along with funding from the Australian National Health. AP and SC are funded through the Medical Research Council (NHMRC) Integrated Systems for Epidemic Response (APP1107393). MK is supported by an NHMRC fellowship (APP1145997) and receives funding from the NHMRC for Integrated Systems for Epidemic Response. The funders did not have any role in the study design, data collection and analysis, decision to publish or preparation of the manuscript.

Author contributions: AP wrote the manuscript and is leading the study; TH, BO, DD, MK supported study design development, TH, BO, DD, MK, SC supported data analysis interpretation and revised the manuscript critically. All authors read and approved the final manuscript.

Acknowledgements: Thank you to the survey respondents for sharing your knowledge and experience. Thank you to TEPHIconnect, FETP programme directors, and TEPHINET networks, for distributing the 
survey to members and for support with recruitment. Thank you also to Dr Kinley Wangdi for support with mapping, and Dr Alice Richardson for statistical advice.

\section{References}

1. O'Carroll P, Kirk M, Baggett K, Herrera D. The Global Field Epidemiology Roadmap [Internet]. 2018 [cited 2020 Sep 9]. Available from:

https://www.tephinet.org/sites/tephinet/files/content/attachment/2018-11-

26/The\%20Global\%20Field\%20Epidemiology\%20Roadmap_11.26.18.FINAL_.pdf

2. World Health Organization. Working for health and growth: investing in the health workforce [Internet]. World Health Organization; 2016 [cited 2020 Sep 11]. Report No.: ISBN 9789241511308. Available from: https://apps.who.int/iris/bitstream/handle/10665/250047/9789241511308eng.pdf;jsessionid=935A6223EF4D1BFCE447E2ABDD915AC3? sequence $=1$

3. Dhama K, Patel SK, Sharun K, Pathak M, Tiwari R, Yatoo MI, et al. SARS-CoV-2 jumping the species barrier: Zoonotic lessons from SARS, MERS and recent advances to combat this pandemic virus. Travel Med Infect Dis. 2020;37:101830.

4. Nsubuga $P$, White $M$, Fontaine R, Simone P. Training programmes for field epidemiology. The Lancet. 2008 Feb 23;371(9613):630-1.

5. Bensyl DM, King ME, Greiner A. Applied Epidemiology Training Needs for the Modern Epidemiologist. Am J Epidemiol. 2019 May 1;188(5):830-5.

6. Thacker SB, Buffington J. Applied epidemiology for the 21st Century. Int J Epidemiol. 2001 Apr;30(2):320-5.

7. Ryu S, Kim YW, Kim S, Liao Q, Cowling BJ, Lee C-S. Occupational Stress among Field Epidemiologists in Field Epidemiology Training Programs from the Public Health Sector. Int $\mathrm{J}$ Environ Res Public Health. 2019 Jan;16(18):3427.

8. Schneider D, Evering-Watley M, Walke H, Bloland PB. Training the Global Public Health Workforce Through Applied Epidemiology Training Programs: CDC's Experience, 1951-2011. Public Health Rev. 2011 Jun;33(1):190-203.

9. Training Programs | TEPHINET [Internet]. [cited 2020 Sep 30]. Available from: https://www.tephinet.org/training-programs

10. Traicoff DA, Walke HT, Jones DS, Gogstad EK, Imtiaz R, White ME. Replicating Success: Developing a Standard FETP Curriculum. Public Health Rep. 2008;123(Suppl 1):28-34.

11. Riley M, Health JBS of P. Concentrations [Internet]. Johns Hopkins Bloomberg School of Public Health. [cited 2020 Oct 24]. Available from: https://www.jhsph.edu/academics/degreeprograms/master-of-public-health/curriculum/concentrations.html

12. London School Hygiene and Tropical Medicine. LSHTM MSc Public Health, programme handbook 2020-21 [Internet]. [cited 2020 Oct 24]. Available from: https://www.Ishtm.ac.uk/files/phhandbook.pdf 
13. Parry, Amy Elizabeth, Kirk, MD, Durrheim, DN, Olowokure, B, Colquhoun, S, Housen, T. Epidemiology emergency response workforce; the need for "collective competence." Pending Publ.

14. Parry AE, Kirk MD, Durrheim DN, Olowokure B, Housen T. Study protocol: building an evidence base for epidemiology emergency response, a mixed-methods study. BMJ Open. 2020 Jun 1;10(6):e037326.

15. Deborah K. Padget. Qualitative and Mixed Methods in Public Health. SAGE Publications; 2012.

16. Teddlie C, Yu F. Mixed Methods Sampling: A Typology With Examples. J Mix Methods Res. 2007 Jan;1(1):77-100.

17. Parry AE, Kirk MD, Colquhoun SM, Housen T. Enhancing the effectiveness of the epidemiology workforce responding to Covid-19. BMJ [Internet]. 2020 Mar 19 [cited 2020 Jul 21];368(m1075). Available from: https://www.bmj.com/content/368/bmj.m1075/rr-0

18. David de Vaus. Surveys in Social Research. 6th edition. Allen \& Unwin - Australia; 2014.

19. Holding M, Ihekweazu C, Stuart JM, Oliver I. Learning from the Epidemiological Response to the 2014/15 Ebola Virus Disease Outbreak. J Epidemiol Glob Health. 2019 Aug;9(3):169-75.

20. About - REDCap [Internet]. [cited 2020 Sep 30]. Available from: https://projectredcap.org/about/

21. StataCorp. Stata Statistical Software. College Station, TX: StataCorp LLC; 2017.

22. QSR International Pty Ltd. NVivo 11 [Internet]. Available from:

https://www.qsrinternational.com/nvivo-qualitative-data-analysis-software/home

23. Liamputtong P. Qualitative Research Methods [Internet]. South Melbourne, Vic., Oxford University Press; 2009 [cited 2018 Jul 25]. Available from: https://trove.nla.gov.au/work/7394612

24. Braun V, Clarke V. Using thematic analysis in psychology. Qual Res Psychol. 2006 Jan 1;3(2):77-101.

25. Regional offices [Internet]. [cited 2020 Sep 30]. Available from: https://www.who.int/about/who-weare/regional-offices

26. Rubinelli S, Myers K, Rosenbaum M, Davis D. Implications of the current COVID-19 pandemic for communication in healthcare. Patient Educ Couns. 2020 Jun;103(6):1067-9.

27. Cooley L. Trust and Communication: Responding to Uncertainty. J Patient Exp. 2020 Jun;7(3):277-8.

28. Finset A, Bosworth H, Butow P, Gulbrandsen P, Hulsman RL, Pieterse AH, et al. Effective health communication - a key factor in fighting the COVID-19 pandemic. Patient Educ Couns. 2020 May;103(5):873-6.

29. Forbes O, Davis S, Dyda A, Rosewell A, Williams S, Moffatt C, et al. Expert Perspectives on Outbreak Investigation Training: A Quality Improvement Exercise. Glob Biosecurity [Internet]. 2020 Jul 7 [cited 2020 Oct 29];1(4). Available from: http://jglobalbiosecurity.com/articles/53/print/

30. Training programmes for field epidemiology - The Lancet [Internet]. [cited 2020 Oct 27]. Available from: https://www.thelancet.com/journals/lancet/article/PIIS0140673608602810/fulltext?rss=yes

31. Jones DS, Dicker RC, Fontaine RE, Boore AL, Omolo JO, Ashgar RJ, et al. Building Global Epidemiology and Response Capacity with Field Epidemiology Training Programs. Emerg Infect Dis. 2017 Dec;23(Suppl 1):S158-65. 
32. Samet JM, Brownson RC. Epidemiology in a Changing World. Am J Prev Med. 2014 Nov 1;47(5):S383-5.

33. Dhatt R, Theobald S, Buzuzi S, Ros B, Vong S, Muraya K, et al. The role of women's leadership and gender equity in leadership and health system strengthening. Glob Health Epidemiol Genomics [Internet]. 2017 ed [cited 2020 Oct 27];2. Available from:

https://www.cambridge.org/core/journals/global-health-epidemiology-and-genomics/article/role-ofwomens-leadership-and-gender-equity-in-leadership-and-health-systemstrengthening/A6AEB63AFE17295E0EF9E40741A2EC5B

34. Johnson C, Williams B. Gender and Political Leadership in a Time of COVID. Polit Gend. 2020 Jun $10 ; 1-8$.

35. Randell S, Yerbury H. An Exploration of the Metaphors and Images Used to Describe Leadership in Two Different Cultural Contexts. Front Educ [Internet]. 2020 [cited 2020 Oct 31];5. Available from: https://www.frontiersin.org/articles/10.3389/feduc.2020.00151/full?utm_source=FAAE\&utm_medium=EMLF\&utm_campaign=MRK_1411754_21_Educat_20200825_arts_A

36. Médecins Sans Frontières (MSF) International. Who we are [Internet]. Médecins Sans Frontières (MSF) International. [cited 2019 Jul 15]. Available from: https://www.msf.org/who-we-are

37. Thoroughman D. Applied Epidemiology Competencies: Experience in the Field. Public Health Rep. 2008;123(Suppl 1):8-10.

38. Pourshaban D, Basurto-Dávila R, Shih M. Building and Sustaining Strong Public Health Agencies: Determinants of Workforce Turnover. J Public Health Manag Pract JPHMP. 2015 Dec;21 Suppl 6:S8090.

39. Gebbie KM. The public health workforce: key to public health infrastructure. Am J Public Health. 1999 May 1;89(5):660-1.

40. Bernard AW, Gorgas D, Greenberger S, Jacques A, Khandelwal S. The Use of Reflection in Emergency Medicine Education. Acad Emerg Med. 2012;19(8):978-82.

41. World Health Organization. Guidance for after action review (AAR) [Internet]. Geneva, Switzerland: World Health Organization; 2019 [cited 2019 Oct 8]. Report No.: WHO/WHE/CPI/2019.4. Available from: https://apps.who.int/iris/bitstream/handle/10665/311537/WHO-WHE-CPI-2019.4-eng.pdf? sequence $=1$

\section{Figures}


Stakeholder analysis Literature review Key informant interviews

\section{Epidemiology emergency responder survey}

Survey part 1:

Applied epidemiology training
Survey part 2:

Emergency response experience

Epidemiology emergency responder in-depth interviews

\section{Figure 1}

Epidemiology emergency workforce research study model (14)

Stakeholder analysis Literature review Key informant interviews

\section{Epidemiology emergency responder survey}

Survey part 1:

Applied epidemiology training
Survey part 2:

Emergency response experience

Epidemiology emergency responder in-depth interviews

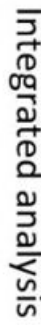
Epidemiology emergency response workforce framework

Figure 1

Epidemiology emergency workforce research study model (14) 


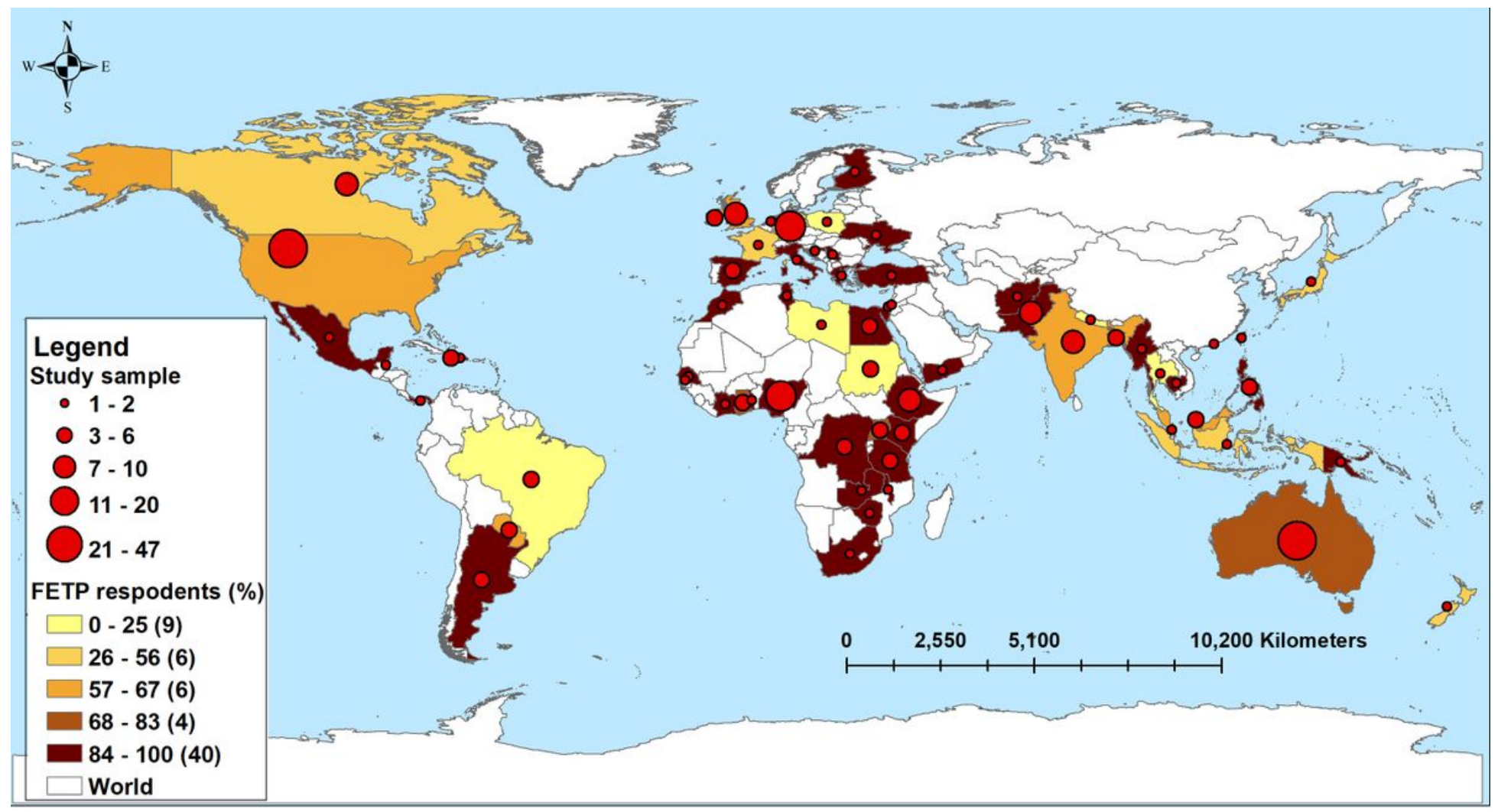

\section{Figure 2}

Distribution of epidemiology emergency response survey respondents by country and percent of Field Epidemiology Training Programme respondents, 2019-2020 ( $n=282)$ Note: The designations employed and the presentation of the material on this map do not imply the expression of any opinion whatsoever on the part of Research Square concerning the legal status of any country, territory, city or area or of its authorities, or concerning the delimitation of its frontiers or boundaries. This map has been provided by the authors. 


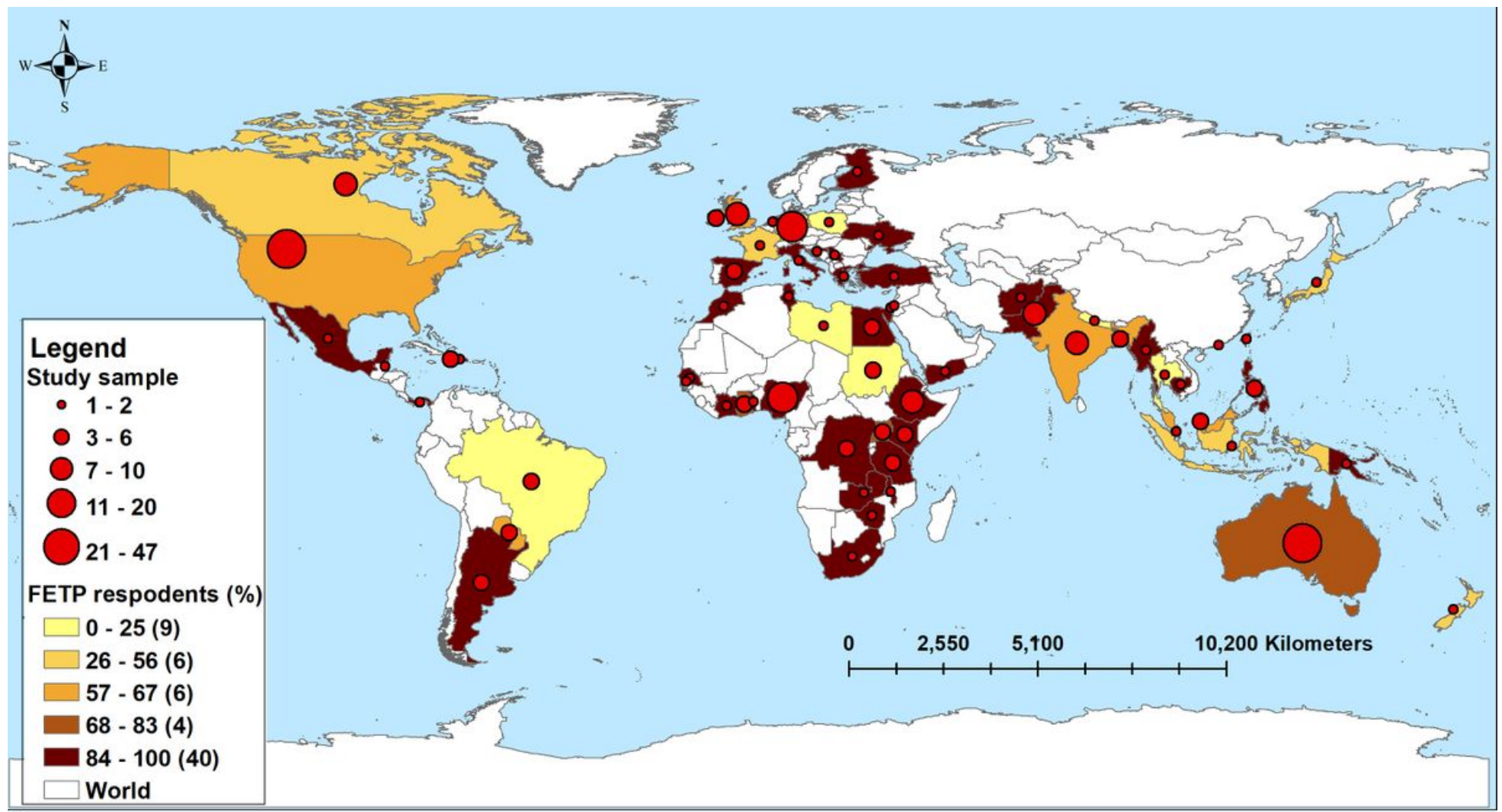

Figure 2

Distribution of epidemiology emergency response survey respondents by country and percent of Field Epidemiology Training Programme respondents, 2019-2020 ( $n=282)$ Note: The designations employed and the presentation of the material on this map do not imply the expression of any opinion whatsoever on the part of Research Square concerning the legal status of any country, territory, city or area or of its authorities, or concerning the delimitation of its frontiers or boundaries. This map has been provided by the authors.

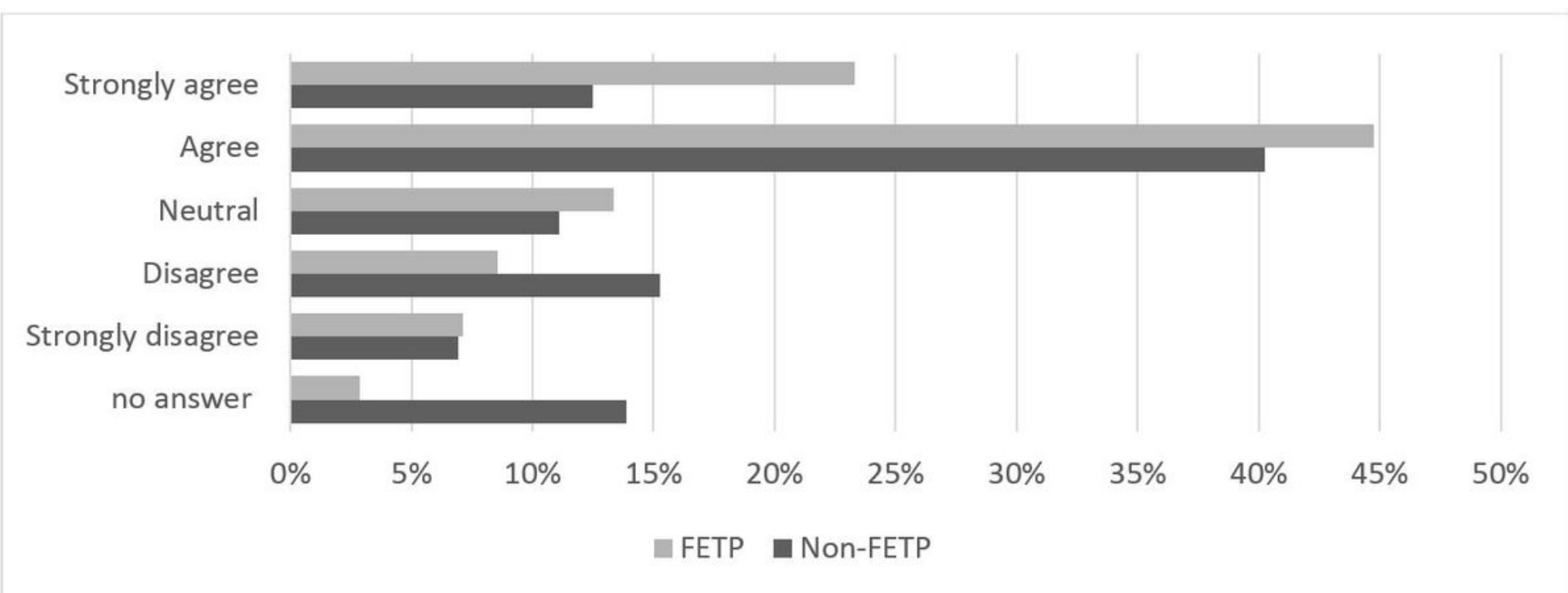

Figure 3 
"Epidemiology training provided the required knowledge to respond to emergencies", comparison of FETP and non-FETP epidemiology emergency response survey respondents, 2019-2020 ( $n=282)$

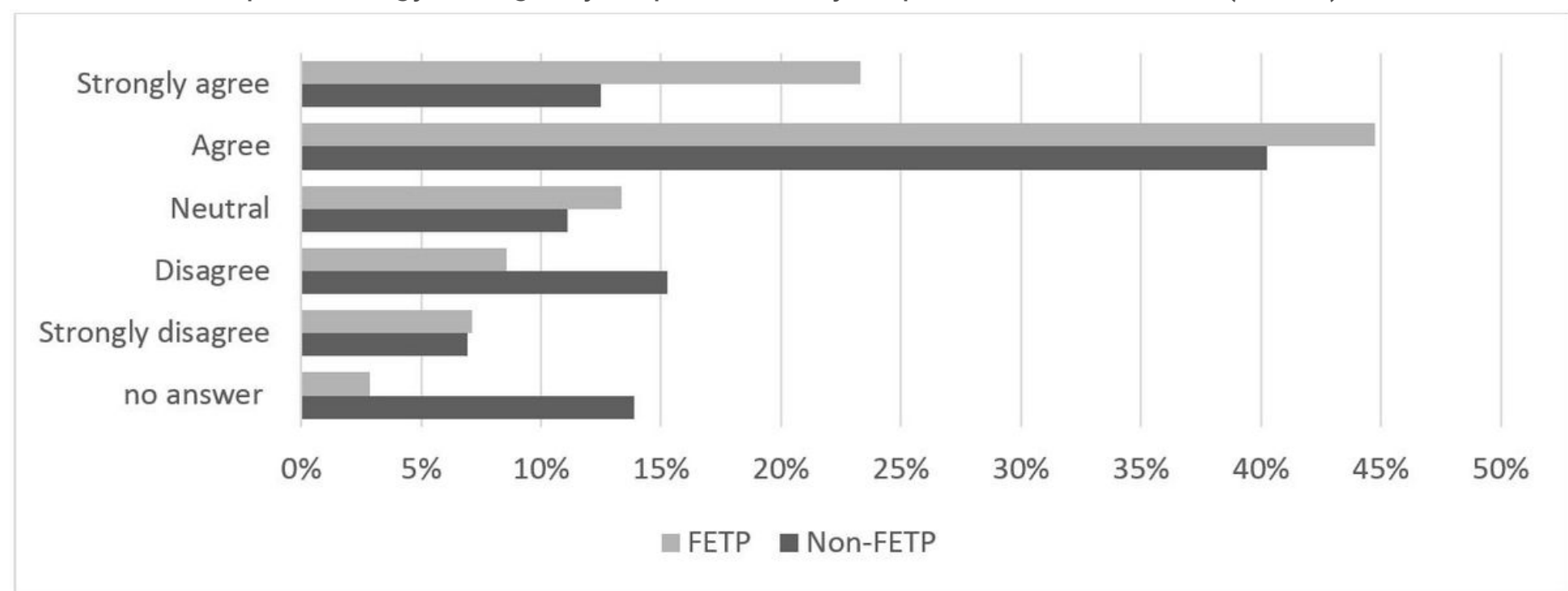

\section{Figure 3}

"Epidemiology training provided the required knowledge to respond to emergencies", comparison of FETP and non-FETP epidemiology emergency response survey respondents, 2019-2020 ( $n=282)$

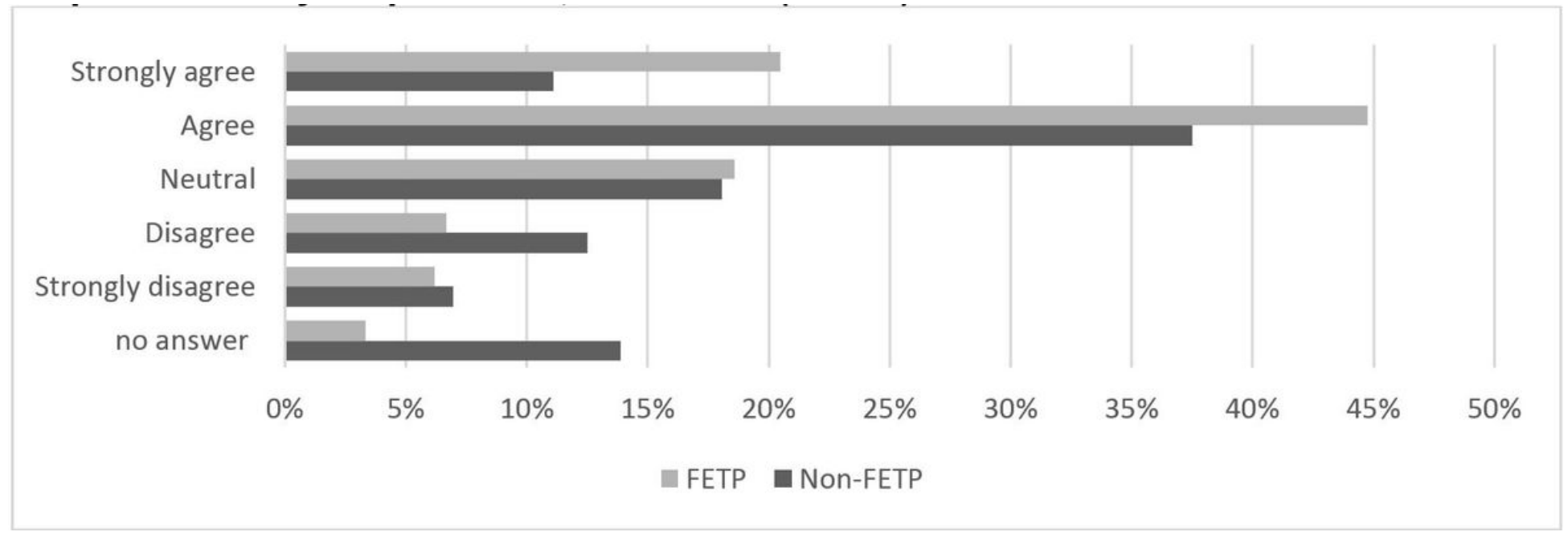

\section{Figure 4}

"Epidemiology training provided the required skills to respond to emergencies", comparison between FETP and non-FETP epidemiology emergency response survey respondents, 2019-2020 ( $n=282)$ 


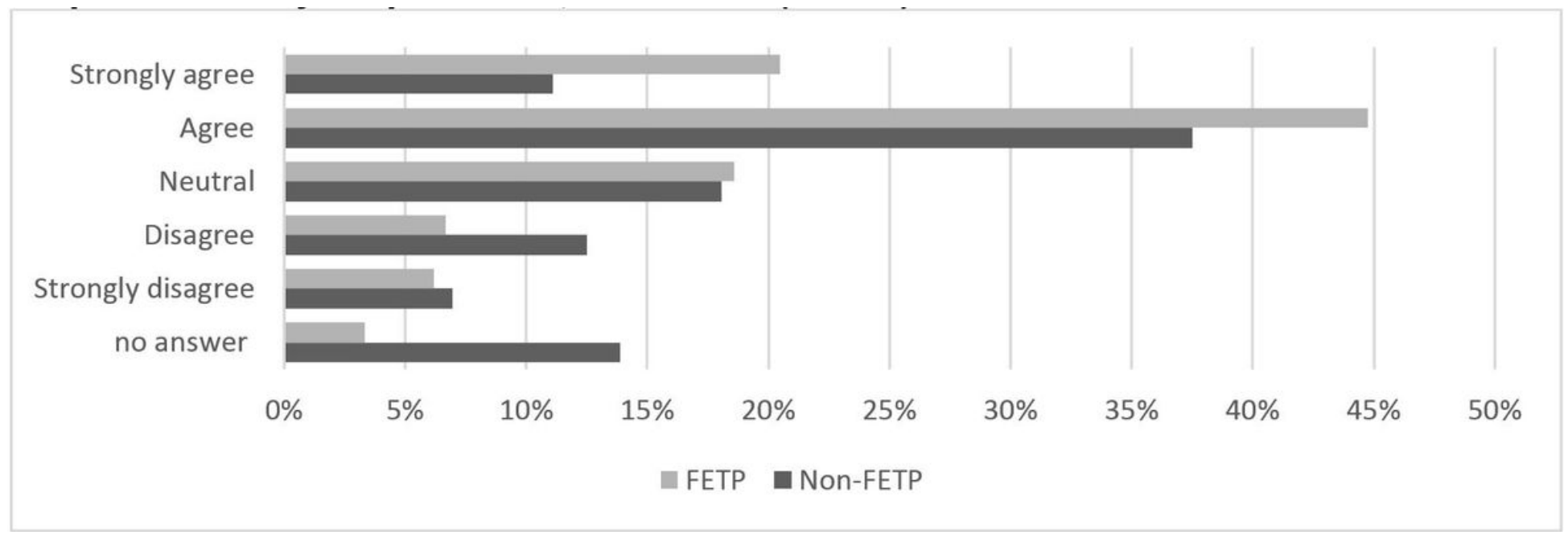

\section{Figure 4}

"Epidemiology training provided the required skills to respond to emergencies", comparison between FETP and non-FETP epidemiology emergency response survey respondents, 2019-2020 ( $n=282)$ 